\title{
Efeitos das queimadas na saúde humana
}

\author{
HELENA Ribeiro e JoÃo VICENTE DE ASSUNÇÃo
}

$\mathrm{O}$ S ESTUDOS dos efeitos das queimadas para a saúde humana são muito escassos, tanto no Brasil quanto no exterior, em que pese quase toda a literatura que trata das emissões atmosféricas produzidas por queima de biomassa mencionar que elas causam efeitos deletérios à saúde. Tal fato se deve em grande parte à variedade de aspectos envolvidos e à dificuldade em se separar causas isoladas de um determinado efeito. Pesquisas em saúde ambiental são bastante complexas à medida em que a saúde humana depende de uma teia de fatores interligados: exógenos (bióticos e abióticos), endógenos (fisiológicos e anatômicos), comportamentais (psicológicos, sociais e culturais) e da densidade demográfica (Audy, 1971).

Alguns autores, como Dubos (1961) e Audy (1971), vêem a saúde como um processo contínuo de reação e adaptação, diferentemente da definição adotada pela Organização Mundial da Saúde em 1946: "Saúde é o estado de completo bem-estar físico, mental e social, e não meramente a ausência de doenças” (Ribeiro, 2001b). Para Dubos (1961), “estados de saúde ou doença são a expressão do sucesso ou fracasso experimentado pelo organismo no seu esforço de resposta adaptável aos desafios do meio ambiente". Para Audy (1971) "saúde é a propriedade contínua, potencialmente mensurável, da habilidade de um indivíduo reagir a insultos químicos, ou físicos, ou infecciosos, ou psicológicos, ou sociais".

No caso das queimadas, estaríamos analisando a influência de fatores exógenos abióticos que poderiam ter um ou mais efeitos diretos, além de desencadear efeitos indiretos, tais como alterações macro e microclimáticas com conseqüências sobre elementos bióticos que, por sua vez, poderiam alterar o equilíbrio saúde/doença numa dada região. Muitos efeitos potenciais para a saúde humana podem resultar direta ou indiretamente das mudanças climáticas. Alterações na prevalência e disseminação de doenças infecciosas, mediadas por processos biológicos, ecológicos, sociais interligados poderiam ter significativo impacto na saúde pública e na sociedade, apesar de ainda não terem sido realizados estudos quantitativos em profundidade para entender tais processos (Chan et al., 1999). Risco de mortalidade por doenças cardiovasculares poderia ser aumentado, sobretudo para populações de baixa renda em países tropicais (Weihe, 1986). 
Pesquisas realizadas por Radojevic \& Hassan (1999) em Brunei Darussalam, nas ilhas Bornéo, indicam alguns dos efeitos que as queimadas de florestas desencadeiam na região: drástica redução da visibilidade, fechamento de aeroportos e escolas, aumento de acidentes de tráfego, destruição da biota pelo fogo, aumento na incidência de doenças, diminuição da produtividade, restrição das atividades de lazer e de trabalho, efeitos psicológicos e custos econômicos. Dentre os sintomas de doenças e doenças observados relatam infecções do sistema respiratório superior, asma, conjuntivite, bronquite, irritação dos olhos e garganta, tosse, falta de ar, nariz entupido, vermelhidão e alergia na pele, e desordens cardiovasculares (Radojevic, 1998).

Outro efeito significativo em termos climáticos é que as partículas em suspensão acabam por interferir no processo de formação de núcleos de condensação, alterando os mecanismos de formação de nuvens e o albedo, conseqüentemente alterando os processos radiativos e os ciclos hidrológicos nas regiões tropicais (Yamasoe et al., 2000). Pesquisas realizadas dentro do projeto SCAR-B indicaram que o raio dos aerossóis emitidos por queimadas teve um aumento de $60 \%$ na atmosfera nos três primeiros dias devido à condensação e à coagulação, indicando uma correlação positiva entre os núcleos de condensação e as concentrações de fumaça que afetam as propriedades das nuvens (Kaufman et al., 1998). O mesmo experimento demonstrou que as partículas em suspensão da fumaça, abaixo de $4 \mathrm{~km}$, faziam uma trajetória que ia da Amazônia para Sul, e em seguida para Leste, deixando o continente nas latitudes $25^{\circ} \mathrm{S}-30^{\circ} \mathrm{S}$. Cálculos de transferência de radiação mostraram um decréscimo da adsorção da radiação solar no sistema atmosférico de superfície devido aos aerossóis da fumaça, em valores que variavam de 5 a $50 \mathrm{~W} \mathrm{~m}^{2}$ (Nobre et al., 1998). Reduções na incidência da radiação fotossinteticamente ativa na ordem de 20 a $45 \%$ foram observadas durante dois meses de queimadas, em comparação a períodos fora da época de queimadas, em várias localidades na parte sul da bacia amazônica. Essas significativas reduções na radiação incidente na superfície devido à grande carga de aerossóis podem ter implicações na produção primária dos ecossistemas sensíveis (Eck et al., 1998). Portanto, em virtude de mudanças nos ecossistemas, há também um risco potencial de alterações na presença de vetores de doenças infecciosas e alterações nas atividades de fotossíntese de cultivos agrícolas que eventualmente podem desencadear efeitos na própria nutrição humana. Existe, sem dúvida, um campo muito amplo de investigações sobre o tema.

Entretanto, como já mencionado, há inúmeras variáveis que poderiam influir na ocorrência destes agravos. Separá-las todas para determinar o efeito isolado de queimadas é bastante difícil e demanda o desenvolvimento de metodologias de pesquisa específicas para cada caso. Em vista disso, neste capítulo estaremos nos restringindo aos principais efeitos da poluição atmosférica da baixa troposfera à saúde, causados por queimadas. Mesmo assim, estes estudos também são bastante escassos e isolados, de modo que teremos de nos ater a 
algumas pesquisas realizadas tanto no exterior quanto no Brasil, e a inferências de potenciais riscos à saúde a partir de dados de medições de poluentes atmosféricos feitas em diferentes locais durante queima de biomassa.

Outro aspecto relevante a se ressaltar é que as queimadas não são homogêneas, assim como seus efeitos para a saúde. Diferentes tipos de biomassa apresentam emissões bastante variadas em termos de gases e de material particulado. Diferentes fases ou estágios das queimadas também apresentam estas variações (Yamasoe et al., 2000).

Assim, a queima de cerrado ou de floresta amazônica apresenta disparidades em termos de emissões. Experiências realizadas no Brasil indicaram que enquanto a queima de cerrado apresentava um padrão bem definido de emissão, dependendo da fase de combustão e da categoria de cerrado, os resultados da floresta tropical foram mais difíceis de interpretar uma vez que não apresentavam uma estrutura relacionada à fase de combustão nem ao tipo de floresta (primária ou secundária). Isso pode se dar em virtude da diversidade das espécies vegetais na floresta, constituída de árvores grossas, folhas e galhos finos que demandam tempo de secagem e de queima diferentes, com diferentes eficiências (Yamasoe et al., 2000). A queima de cana-de-açúcar antes da colheita, de pastagens, ou de terrenos com restos de culturas antes de um novo plantio, também apresenta emissões diferentes e, infelizmente, elas não vêm sendo estudadas de forma sistemática no Brasil, ou mesmo em outros países, onde essas práticas agrícolas são bastante comuns, sobretudo para o combate às pragas. Há algumas pesquisas isoladas cujos resultados não podem ser extrapolados para outras regiões.

Da mesma forma, estudos realizados durante a queima de florestas em países frios ou temperados, que são mais abundantes, podem servir apenas de referências para fenômenos mais globais, uma vez que as espécies vegetais são muito diferentes das espécies tropicais, com predomínio de coníferas que emitem componentes específicos. Mesmo queimadas em florestas de coníferas apresentam marcantes diferenças dependendo do país, do tipo de pinus, ou do tipo de queima - se do dossel ou do solo. Conard \& Ivanova (1997) comentam a dificuldade de se obter boas estimativas de emissões de incêndios florestais por conta das variações espaciais e temporais na intensidade e severidade do fogo. Os tipos de incêndios que ocorrem nas florestas dos EUA e da Rússia são muito diferenciados, levando a erros potenciais na estimativa de emissões atmosféricas.

Por outro lado, os efeitos sobre a saúde pública são bastante diversos dependendo da maior ou menor exposição dos grupos ou indivíduos. Bombeiros e combatentes de queimadas, sem dúvida, constituem o grupo com mais alto risco de envenenamento. Estudos feitos nos EUA sobre envenenamento por monóxido de carbono demonstraram que a segunda causa de envenenamento por CO naquele país provém de inalação de fumaça causada por incêndios, dentre eles os incêndios florestais (Varon et al., 1999). 
Quanto maior a proximidade da queimada, geralmente é maior o seu efeito à saúde. Mas a direção e a intensidade das correntes aéreas têm muita influência sobre a dispersão dos poluentes atmosféricos e sobre as áreas afetadas pela pluma oriunda do fogo. Se os ventos predominantes dirigirem-se para áreas urbanas ou áreas densamente povoadas, um número maior de pessoas estarão sujeitas aos efeitos dos contaminantes aéreos. É o caso do Sudeste Asiático, onde queimadas provocam névoa de poluentes de extensão regional com impactos à saúde de centenas de milhões de pessoas.

Um episódio de queimada ocorrido no Sudeste Asiático excedeu o padrão estabelecido pela Organização Mundial da Saúde (OMS) para partículas em suspensão menores que $10 \mu \mathrm{m}$ (PM10), atingindo $70 \mu \mathrm{g} / \mathrm{m}^{3}$ para uma média de 24 horas, em 54 dias durante o período de 1 de fevereiro a 30 de abril de 1998. As médias diárias de PM10 ficaram abaixo de $450 \mu \mathrm{g} / \mathrm{m}^{3}$ (1), mas concentrações acima de $600 \mu \mathrm{g} / \mathrm{m}^{3}$ persistiram por muitas horas, durante vários dias, em Brunei Darussalam (Radojevic \& Hassan, 1999).

Grandes cidades, como Kuala Lumpur e Singapura, sofrem de maneira semelhante: conforme foi registrado durante o ano de 1997, quando todo arquipélago indonésio enfrentou uma grande seca associada ao fenômeno El Nino, que ocasionou um incêndio, o qual atingiu mais de nove milhões de hectares cobertos por floresta de várzea e por floresta secundária, que havia se desenvolvido após o corte de árvores por madeireiros. Queimadas para o preparo do solo para agricultura foram consideradas a causa principal do incêndio (Stolle \& Tomich, 1999). Naquele ano, o impacto do fogo na qualidade do ar da Indonésia e regiões ao redor foi significativo. O índice de qualidade do ar alcançou o valor inédito de $839 \mu \mathrm{g} / \mathrm{m}^{3}(2)$ em Kushing, na Malásia. Milhões de pessoas foram afetadas tanto na Indonésia quanto na Malásia, mas partículas de fumaça chegaram até a Tailândia e as Filipinas (Fang et al., 1999). Esse não foi um caso isolado, uma vez que o fenômeno de névoa causada por queimadas constitui um problema recorrente em Singapura, e no Sudeste Asiático em geral (Koe et al., 2001).

No Brasil, o fenômeno também é bastante recorrente e só não traz conseqüências mais sérias à saúde pública porque as densidades demográficas nas quais ocorre são mais baixas que no Sudeste Asiático. De fato, o fogo é um problema freqüente no que resta das florestas tropicais do mundo (Cochrane, 2000).

As queimadas em florestas tropicais brasileiras estão ligadas à maneira como a ocupação humana vem ocorrendo. Na região amazônica, a ocupação acontece a partir de pulsos migratórios que visam o garimpo e/ou a abertura de fronteiras agrícolas. Um dos episódios mais importantes registrados foi o incêndio de 1998, em Roraima, no qual queimadas usadas para limpar pastagens, savanas e restos de floresta derrubada escaparam ao controle humano e acabaram por destruir uma enorme área, em torno de $40 \mathrm{mil} \mathrm{km}^{2}$, ou cerca de $20 \%$ do estado, cuja área é de $225.116 \mathrm{~km}^{2}$. Os efeitos ao meio ambiente foram dramáticos e 
aqueles referentes à saúde humana só não se tornaram dramáticos também porque o estado têm uma população de apenas 250 mil habitantes. O risco de ocorrência de eventos semelhantes é grave, pois a mesma situação verificada em Roraima se reproduz ao longo do grande arco de desmatamento ao sul da Amazônia, de Rondônia ao Maranhão (Nascimento et al., 2000).

As queimadas, porém, não estão restritas à Amazônia; em quase todo o país são utilizadas para limpar pastagens e restos de colheitas. Além disso, são usadas para facilitar colheita nas extensas, áreas cobertas por canaviais, sobretudo no estado de São Paulo e na Zona da Mata Nordestina.

\section{Emissões atmosféricas}

Queimada é uma combustão incompleta ao ar livre, e depende do tipo de matéria vegetal que está sendo queimada, de sua densidade, umidade etc., além de condições ambientais, em especial a velocidade do vento. Por ser uma combustão incompleta, as emissões resultantes constituem-se inicialmente em monóxido de carbono (CO) e matéria particulada (fuligem), além de cinza de granulometria variada. Resultam também dessa combustão compostos orgânicos simples e complexos representados pelos hidrocarbonetos (HC), entre outros compostos orgânicos voláteis e semivoláteis, como matéria orgânica policíclica - hidrocarbonetos policíclicos aromáticos, dioxinas e furanos, compostos de grande interesse em termos de saúde pública, pelas características de alta toxicidade de vários deles. Como nas queimadas a combustão se processa com a participação do ar atmosférico, há também emissões de óxidos de nitrogênio (NOx), em especial o óxido nítrico $(\mathrm{NO})$ e o dióxido de nitrogênio $\left(\mathrm{NO}_{2}\right)$, formados pelo processo térmico e pela oxidação do nitrogênio presente no vegetal.

Além das emissões diretas (poluentes primários), ocorrem na atmosfera reações entre essas emissões e vários outros compostos presentes no ar, como as reações fotoquímicas com importante participação da radiação ultravioleta do sol, resultando em compostos que podem ser mais tóxicos que os seus precursores: o ozônio $\left(\mathrm{O}_{3}\right)$, os peroxiacil nitratos (PAN) e os aldeídos.

Dióxido de enxofre também é emitido, pois apesar de que em quantidades muito pequenas, os vegetais contém enxofre.

Na Califórnia, segundo Darley (1979), apud Jenkins et al. (1992), as emissões provenientes de queimadas na agricultura, por tonelada de material seco queimado, atingem $3,7 \mathrm{~kg}$ de material particulado; $63,8 \mathrm{~kg}$ de monóxido de carbono $(\mathrm{CO}) ; 4,85 \mathrm{~kg}$ de hidrocarbonetos $(\mathrm{HC}) ; 2,8 \mathrm{~kg}$ de óxidos de nitrogênio (NOx) e 1,65 kg de dióxido de enxofre $\left(\mathrm{SO}_{2}\right)$. A estimativa das emissões totais desses compostos pelas queimadas na agricultura seria de 97 mil toneladas por ano. A contribuição relativa seria de $4,9 \%$ para o material particulado, $82 \%$ para o monóxido de carbono, 6,7\% para os hidrocarbonetos, $4,35 \%$ para os óxidos de nitrogênio e 2,06\% para o dióxido de enxofre. Com relação às emissões atmos- 
féricas totais naquele estado norte-americano, a participação das emissões de queimadas na agricultura é pequena, estimada em $0,13 \%$ para material particulado, $1,27 \%$ para monóxido de carbono, $0,27 \%$ para hidrocarbonetos, $0,38 \%$ para óxidos de nitrogênio e 1,16\% para dióxido de enxofre, com 95\% das emissões originando-se da queima de quatro culturas: arroz, amêndoas, nozes e trigo.

As queimadas de florestas atingem espécies de vários tipos, diferentes portes e grande diversidade em termos de densidade. De acordo com dados fornecidos pela USEPA (1996), os fatores de emissão para queimadas em várias regiões dos EUA, apresentam média geral representada pelos seguintes valores: $324 \mathrm{~kg} / \mathrm{ha}$ para material particulado; $2670 \mathrm{~kg} / \mathrm{h}$ a para monóxido de carbono; $458 \mathrm{~kg} /$ ha para compostos orgânicos voláteis e $76 \mathrm{~kg} / \mathrm{ha}$ para óxidos de nitrogênio. Para a região Sul dos EUA, os fatores de emissão correspondem a 172 $\mathrm{kg} \mathrm{MP} / \mathrm{ha}, 1410 \mathrm{~kg} \mathrm{CO} / \mathrm{ha}, 242 \mathrm{~kg} \mathrm{VOC} / \mathrm{ha}$, e $40 \mathrm{~kg} \mathrm{NOx} / \mathrm{ha}$, ou seja, valores abaixo da média global do país.

O trabalho desenvolvido por Yamazoe et al.(2000) com relação à composição dos aerossóis de emissões de queimadas na Amazônia mostrou que as espécies dominantes eram carbono, íon potássio $\left(\mathrm{K}^{+}\right)$, íon cloro $\left(\mathrm{Cl}^{-}\right)$e íon sulfato $\left(\mathrm{SO}_{4}\right)^{2-}$. Essa presença de cloro pode explicar a formação de compostos considerados altamente tóxicos, na classe das dioxinas e dos furanos.

Araújo et al. (1999) apresentam estimativa de emissão de monóxido de carbono $(\mathrm{CO})$ e de dióxido de carbono $\left(\mathrm{CO}_{2}\right)$ para queimada e pós-queimada obtida na devastação da floresta tropical na região amazônica no estado do Pará, por experimento em área virgem de três hectares, que foi cortada e deixada secar por três meses. A pós-queima foi feita 30 dias após a queimada principal. Os valores obtidos foram, para monóxido de carbono, 4,6 t/ha na queima inicial e $0,4 \mathrm{t} / \mathrm{ha}$ na pós-queima; para dióxido de carbono, $65,1 \mathrm{t} / \mathrm{ha}$ na queima inicial e $5,1 \mathrm{t} /$ ha na pós-queima. Importante notar que o valor encontrado para monóxido de carbono $(4,6 \mathrm{t} / \mathrm{ha})$ na queimada inicial é relativamente próximo do fator de emissão médio da USEPA para os EUA $(2,67$ t/ha).

\section{Poluentes e riscos à saúde pública}

Nas queimadas são emitidos vários poluentes clássicos, entre eles NOx, $\mathrm{CO}, \mathrm{HC}$ e material particulado, além de substâncias altamente tóxicas. O efeito agudo à saúde da população em geral fica restrito àquelas pessoas mais próximas à área da queimada, em especial as que estejam atuando no seu combate. O efeito pode ir de intoxicação até a morte por asfixia, pela redução da concentração de oxigênio em níveis críticos e pela elevação no nível de monóxido de carbono, que compete com o oxigênio na sua ligação com a hemoglobina. Por outro lado as concentrações dos poluentes clássicos, exceto material particulado, não têm atingido níveis que excedam os limites recomendados pela Organização Mundial da Saúde e aqueles adotados no Brasil como padrões de qualidade do ar. Os 
níveis registrados mostram elevação da concentração de background na região, mas freqüentemente essas concentrações têm sido medidas bem acima do nível do solo, portanto, longe da zona respiratória da população. A quantidade de calor gerada nas queimadas faz com que a densidade dos gases se torne menor do que a do ar, causando a elevação dos gases resultantes e de partículas, que atingem alturas consideráveis durante o processo de dispersão da fumaça na atmosfera.

Os níveis de $\mathrm{CO}_{2} \mathrm{O}_{3}$ registrados por Kirchof (1989) em altitudes de 1000 a $6000 \mathrm{~m}$ do solo em área atingida por queimada de cana alcançaram máximos de monóxido de carbono e de ozônio entre 1500 a $2000 \mathrm{~m}$ de altitude, com valores de monóxido de $600 \mathrm{ppb}$ e $80 \mathrm{ppb}$ de ozônio, quando o normal seria $100 \mathrm{ppb}$ de $\mathrm{CO}$ e $30 \mathrm{ppb}$ de $\mathrm{O}_{3}$. Este nível de $\mathrm{CO}$ está muito abaixo do limite recomendado pela OMS (WHO, 2000) para exposição de oito horas (10 mil ppb) e o nível de ozônio ultrapassa o nível recomendado pela OMS (WHO, 2000), que é de 60ppb, também para exposição de oito horas. Em exposições mais curtas os níveis toleráveis são mais altos. Deve-se observar que o ozônio é proveniente de reações fotoquímicas na atmosfera, principalmente entre óxidos de nitrogênio e hidrocarbonetos, normalmente não sendo resultado apenas das emissões das queimadas.

Por outro lado, o fato das pessoas se sentirem "asfixiadas" quando presentes numa região de queimadas, onde o oxigênio é consumido rapidamente, faz com que adotem autoproteção e se dirijam para áreas menos críticas. Contudo, existem casos de queimadas de grande intensidade, que podem atingir áreas habitadas e ocasionar danos agudos ou mesmo irreparáveis, como mortes. Efeito muito importante com relação a esses poluentes é o seu potencial de aumentar a concentração de background, que pode agravar situações de poluição de origem urbana e trazer conseqüências a médio e longo prazos.

Como mencionado anteriormente, fontes diferentes de poluição do ar geram emissões diferentes, que têm efeitos específicos sobre a saúde humana.

A avaliação dos efeitos da poluição causada pela queima de biomassa à saúde humana pode envolver diversos profissionais: médicos clínicos para verificar a saúde dos indivíduos expostos, toxicólogos para definir os danos causados pelo poluente, epidemiólogos e geógrafos ligados à medicina para identificar os efeitos sobre grupos expostos. No entanto, como já afirmado em item anterior, estudos nessa área são escassos.

Os principais riscos à saúde humana decorrentes dos poluentes atmosféricos foram avaliados, sobretudo, por estudos realizados em áreas urbanas, preocupados com emissões atmosféricas de origem industrial ou veicular. Os riscos resultantes das queimadas, entretanto, podem ser parcialmente inferidos a partir de pesquisas em áreas urbanas, pois já existem dados disponíveis sobre os níveis de alguns poluentes emitidos durante as queimadas. 
A literatura especializada indica que os principais efeitos à saúde humana da poluição atmosférica são problemas oftálmicos, doenças dermatológicas, gastro-intestinais, cardiovasculares e pulmonares, além de alguns tipos de câncer. Efeitos sobre o sistema nervoso também podem ocorrer após exposição a altos níveis de monóxido de carbono no ar. Além disso, efeitos indiretos podem ser apontados em decorrência de alterações climáticas provocadas pela poluição do ar. Um aumento na temperatura do ar tem impactos na distribuição da flora e da fauna e, conseqüentemente, influencia a distribuição de doenças transmitidas por vetores.

Como a maioria das doenças têm fatores etiológicos múltiplos, a tarefa de avaliar os efeitos à saúde humana da poluição do ar não é fácil e não há base científica para se quantificar todos os seus riscos.

A realização de pesquisas científicas tem enfocado principalmente os efeitos da poluição do ar sobre as doenças respiratórias, cuja associação é mais fácil de se evidenciar.

\section{Poluição do ar e doenças respiratórias}

\section{Quadro conceitual}

Os estudos têm adotado o quadro conceitual da avaliação da exposição humana. A exposição consiste em contato entre a pessoa e uma concentração específica de contaminante ambiental, num determinado período de tempo (CxT). A presença de um poluente no ar é evidência da exposição humana. A exposição pessoal é a presença de um poluente na zona de respiração de um indivíduo. Dose inalada ou potencial é o produto da concentração do poluente no ar e o volume de ar inspirado.

Tais conceitos têm implicações sobre a saúde. A exposição total de um indivíduo dependerá do tempo despendido em diferentes microambientes e nos padrões de atividade. Por exemplo, exercícios aeróbicos podem levar a uma maior dose inalada; crianças também recebem dose potencialmente maior que os adultos porque aquelas apresentam maior ventilação por massa corporal que estes e geralmente são mais ativas e passam mais tempo em áreas externas (Commitee of the Environmental..., 1996).

Os estudos que vêm sendo realizados tiveram duas abordagens: toxicológica e epidemiológica.

\section{Estudos toxicológicos}

Feitos em laboratórios, fornecem informação sobre o nível em que os diferentes poluentes começam a apresentar efeitos agudos à saúde de animais ou seres humanos. 
Ensaios com animais são feitos para prever efeitos em seres humanos. Apesar da extrapolação de resultados em animais para humanos apresentar limitações, tais pesquisas podem usar métodos que não seriam possíveis ou éticos em seres humanos, incluindo estudos de longo prazo, coleta de tecidos, tentativas de induzir câncer etc. Por essas razões, os estudos com animais têm sido proveitosos na previsão de respostas negativas a produtos químicos na atmosfera e constituem a base de dados disponível para avaliações de risco.

Estudos in vitro incluem ensaios químicos de poluentes com células ou substratos de interesse, mediante biópsias e cultura de células. Seus resultados, apesar de importantes, precisam ser interpretados com cautela.

Estudos com exposição humana controlada são realizados para caracterizar as reações de crianças e adultos normais, ou de subgrupos específicos (asmáticos cardíacos etc.) aos poluentes. Eles podem envolver grupos pequenos e homogêneos que inalam poluentes usando uma máscara, ou respiram normalmente numa câmara ambiental. Esse tipo de estudo provê evidência de efeitos agudos à saúde causados por um componente específico ou por uma mistura de poluentes. Permite também a identificação de pessoas mais sensíveis. Esses métodos apresentam limitações por ser muito difícil reproduzir-se num laboratório todas condições do ar ambiental; poderem caracterrizar somente um número restrito de dose-respostas agudas e subcrônicas; serem impraticáveis para estudos de longo prazo; requererem recursos e infra-estrutura consideráveis; apresentarem problemas éticos.

\section{Estudos Epidemiológicos}

Tais estudos avaliam a associação entre a exposição em diferentes níveis de poluição e os efeitos à saúde de uma dada comunidade, e têm dois objetivos:

- comparar alterações temporais nas condições do ar com flutuações nas taxas de mortalidade ou morbidade. Neste caso, os estudos têm enfocado sobretudo efeitos a curto prazo. Em geral, episódios críticos de poluição do ar têm sido correlacionados com admissões hospitalares, consultas médicas, faltas à escola ou ao trabalho, ou dados de mortalidade;

- avaliar efeitos a longo prazo, comparando dados de mortalidade e morbidade de áreas com diferentes níveis de poluição do ar. Estes estudos têm se baseado em medição da função respiratória, em raios $\mathrm{X}$, ou em questionários e entrevistas feitas em uma amostra selecionada da população envolvida.

Os estudos continuam buscando metodologias que eliminem todos os outros fatores passíveis de causar ou agravar doenças respiratórias, que podem interferir nos resultados: diferenças sociais, hábito de fumar, tempo de residência ou de permanência na área poluída, susceptibilidade individual, fatores psicológicos e emocionais, história prévia de doenças etc (Ribeiro, 2001a). 
É importante ressaltar que, desde 1970, novas metodologias vêm sendo desenvolvidas e testadas para estudos epidemiológicos e toxicológicos neste campo, incluindo o uso de modelos estatísticos para relacionar sintomas respiratórios de asmáticos com níveis de poluentes no ar, condições climáticas etc. Também, datam desse período os estudos pioneiros sobre efeitos à saúde dos poluentes fotoquímicos e efeitos à saúde de populações de risco: aquelas com doenças respiratórias e cardiovasculares, anêmicas, bebês e idosas. Tais estudos visam a estabelecer parâmetros para proteger a saúde em ambientes internos e externos (WHO, 1979).

Relatório da Organização Mundial da Saúde indicou que a exposição humana pode se dar por inalação, ingestão ou contato com a pele, mas a inalação pode ser considerada a via mais importante e mais vulnerável.

Alguns países em desenvolvimento com problemas agudos de má qualidade do ar nas cidades também começaram a realizar estudos sobre efeitos da poluição do ar à saúde nos anos 70. Exemplos são aqueles desenvolvidos nas áreas metropolitanas de São Paulo e do Rio de Janeiro, no Brasil, e na Cidade do México. Nos países em desenvolvimento o foco tem sido para poluentes de origem industrial e veicular. Neles, igualmente, os estudos dos efeitos dos poluentes derivados de queimadas são praticamente inexistentes.

No próximo tópico são apresentados os principais efeitos adversos à saúde humana de poluentes específicos, apesar de se reconhecer a ocorrência de poluentes.

\section{Principais efeitos na saúde humana dos poluentes emitidos por queima de biomassa}

\section{Efeitos à saúde do material particulado}

Dependendo da origem, da composição química e do tamanho da partícula, o efeito do material particulado é diferente. As partículas maiores (5 a 30um de diâmetro) depositam-se, pelo impacto da turbulência do ar, no nariz, na boca, na faringe e na traquéia. Partículas de 1 a $5 \mu \mathrm{m}$, geralmente depositam-se por sedimentação na traquéia, nos brônquios e nos bronquíolos. Partículas com menos de $1 \mu \mathrm{m}$ de diâmetro, em geral depositam-se por difusão nos pequenos bronquíolos e alvéolos (WHO, 1979).

A meia-vida biológica das partículas varia de alguns dias a vários anos, dependendo de sua composição. Partículas solúveis podem se dissolver no catarro e, neste caso, serão provavelmente eliminadas por expectoração ou engolidas e removidas pelo sistema digestivo. Nos alvéolos elas podem se dispersar nos sistemas linfático ou sangüíneo e ser removidas dos pulmões. A remoção de partículas insolúveis não é bem conhecida. 
O transporte mucociliar e a conseqüente remoção das partículas podem ser afetados pelo hábito de fumar, por infecção aguda do sistema respiratório, por doença pulmonar obstrutiva crônica e por inalação de dióxido de enxofre.

Todos os estudos sobre emissões atmosféricas produzidas por queimadas têm indicado o material particulado como um dos mais impactantes, sobretudo o particulado inalável (PM10).

Dentre os efeitos detectados em inúmeras pesquisas realizadas por variadas metodologias, em diferentes locais e países sobre concentrações de material particulado inalável (PM10) acima das recomendações, encontrou-se aumento de sintomas respiratórios em crianças, aumento de doenças respiratórias em crianças, diminuição da função pulmonar em crianças, aumento da mortalidade em pacientes com doenças cardiovasculares e/ou pulmonares, aumento e piora dos ataques de asma em asmáticos, aumento de casos de câncer devido a efeitos de partículas cuja composição química contém componentes carcinogênicos (Commitee of the Environmental..., 1996).

Estudos realizados nas últimas décadas têm demonstrado que o material particulado em suspensão pode causar efeitos, mesmo em níveis abaixo dos padrões de qualidade do ar que têm sido fixados em vários países desenvolvidos, e também no Brasil. Estudos epidemiológicos realizados em regiões urbanas, ou seja, para o particulado em suspensão nessas áreas têm sido incapazes de definir um nível abaixo do qual não haja ocorrência de efeitos à saúde humana (WHO, 2000). Esse material particulado urbano tem na sua constituição produtos da combustão incompleta em veículos automotores, fornos, caldeiras etc.

Aumento da mortalidade, aumento da admissão hospitalar, maior uso de broncodilatadores, exacerbação de sintomas, tosse, diminuição do pico do fluxo expiratório, estão diretamente associados à concentração de material particulado, conforme mostram as equações a seguir (WHO, 2000).

Mortalidade com relação a:

- concentração de partículas inaláveis (PM10): $\mathrm{y}=(0,07 \pm 0,012) \mathrm{x}$

- concentração de partículas respiráveis $(\mathrm{PM} 2,5): \mathrm{y}=(0,151 \pm 0,012) \mathrm{x}$

- sulfatos: $\mathrm{y}=0,6 \mathrm{x}$

Admissões hospitalares com relação a:

- concentração de partículas inaláveis (PM10): y $=(0,084 \pm 0,033) \mathrm{x}$

- concentração de partículas respiráveis $(\mathrm{PM} 2,5):-\mathrm{y}=0,5 \mathrm{x}$

- sulfatos: $\mathrm{y}=0,6 \mathrm{x}$

Uso de bronco-dilatadores, associado a:

- concentração de partículas inaláveis $($ PM10): $\mathrm{y}=(0,337 \pm 0,132) \mathrm{x}$ 
Exacerbação de sintomas, associada a:

- concentração de partículas inaláveis $($ PM10): $\mathrm{y}=(0,345 \pm 0,162) \mathrm{x}$

Tosse associada a:

- concentração de partículas inaláveis (PMl0): y $=(0,455 \pm 0,228) \mathrm{x}$

Redução do pico do fluxo expiratório associada a:

- concentração de partículas inaláveis $($ PM10): $\mathrm{y}=(0,013 \pm 0,004) \mathrm{x}$

Em todas essas equações, $\mathrm{x}$ é a concentração de material particulado em micrograma por metro cúbico $\left(\mu \mathrm{g} / \mathrm{m}^{3}\right)$, e y a alteração ocorrida em porcentagem. Nessas equações são mostrados os intervalos de confiança para nível de confiança de $95 \%$ e são válidas entre $20 \mu \mathrm{g} / \mathrm{m}^{3}$ e $200 \mu \mathrm{g} / \mathrm{m}^{3}$ no caso de PM10, e de $10 \mu \mathrm{g} / \mathrm{m}^{3}$ a $100 \mu \mathrm{g} / \mathrm{m}^{3}$ no caso de PM2,5.

O material particulado de queimadas teria efeito similar, ou até maior, pelo seu alto conteúdo de produtos de combustão incompleta, o que significaria risco à saúde proporcional à concentração de material particulado presente.

Um dos raros estudos procedidos no Brasil para se avaliar efeitos na saúde respiratória de queimadas foi realizado na cidade de Araraquara e visou verificar impactos da queima da cana-de-açúcar antes da colheita. No Brasil, o corte da cana-de-açúcar geralmente é feito à mão, e antes de ser cortada toda a plantação é incendiada para proteger os trabalhadores das folhas afiadas, dos insetos e de cobras venenosas. A fumaça representa um risco aos motoristas nas estradas e um incômodo aos moradores das cidades vizinhas.

Araraquara, com 173 mil habitantes, foi escolhida para sediar uma pesquisa epidemiológica por ser cercada de imensas plantações de cana-de-açucar. No período de $1^{\circ}$ de junho a 31 de agosto, quatro recipientes com $177 \mathrm{~cm}^{2}$ de área foram colocados em pares em pontos estratégicos da cidade (um par no centro, outro na periferia) para coletar partículas, considerando-as como uma estimativa das partículas de fumaça depositadas em Araraquara. Esses dados foram comparados com o número de visitas hospitalares e de pacientes que necessitaram de inalação em um dos principais hospitais da cidade. A associação entre o peso do sedimento e o número de visitas foi avaliada por um modelo de regressão, controlado para sazonalidade, temperatura, dia da semana e chuva. Os pesquisadores encontraram uma significativa relação dose-dependente entre o número de visitas e a quantidade de sedimentos. O risco relativo de visita associado com um aumento de $10 \mathrm{mg}$ de peso de sedimento foi de $1,09(1-1,19)$ e o risco relativo de necessidade de inalação foi de 1,20 $(1,03-1,39)$ nos dias mais poluídos. Os resultados levaram a concluir que a queima de cana pode ter efeitos deletérios à saúde da população exposta (Arbex et al., 2000). 
A "Rede de Avaliação da Qualidade do Ar do Interior" da Companhia de Tecnologia de Saneamento Ambiental (CETESB) do estado de São Paulo, composta de 18 estações de monitoramento em 17 municípios paulistas, vem registrando dados de regiões nas quais predominam lavouras de cana-de-açúcar e queimadas. Todas elas registraram, em 1998, médias aritméticas anuais de fumaça abaixo do padrão primário de $60 \mu \mathrm{g} / \mathrm{m}^{3}$. Mas algumas localizadas em regiões canavieiras, como Ribeirão Preto e Limeira, apresentaram concentrações acima do padrão secundário de $40 \mu \mathrm{g} / \mathrm{m}^{3}$. Em Ribeirão Preto as médias anuais têm se mantido muito próximas da ultrapassagem do padrão primário anual, sem que, no entanto, qualquer episódio de ultrapassagem do padrão diário tenha sido ali registrado (CETESB, 1999).

Por outro lado, pesquisa realizada em quatro municípios do interior paulista - Atibaia, Campinas, Ribeirão Preto e São José dos Campos - mostrou que Ribeirão Preto apresentava ocorrência mais baixa de doenças respiratórias crônicas entre 1990 e 1992, de acordo com uma amostra de 5\% dos prontuários de pacientes de cinco postos de saúde do município. A freqüência relativa de doenças respiratórias crônicas no total dos postos amostrados por pessoas foi $1,58 \%$, em Ribeirão Preto, 1,80\%, em Atibaia, 4,27\% em José dos Campos e 6,31\% em Campinas. As freqüências mais elevadas ocorreram nos municípios com perfil mais industrial, como Campinas e São José dos Campos. Foi detectada tendência ao aumento do risco de consultas relativas a doenças respiratórias nos períodos mais frios do ano (Miranda et al., 1995). Esse último dado pode indicar alguma influência das queimadas de cana, uma vez que estas são feitas nos meses de inverno. Postos de saúde localizados em Usinas de Açúcar e Álcool em outros municípios do estado também registram números elevados de consultas motivadas por sintomas de doenças respiratórias durante os meses de inverno (3).

Medições realizadas em Brunei, durante episódio de névoa causada por queimada e em período de ar límpido sem queimada, são bastante significativas quanto aos impactos da queima da biomassa, uma vez que a região normalmente apresenta ar bastante limpo por não possuir atividade industrial, nem número significativo de veículos em circulação. Em Bandar Seri Begawan, capital de Brunei, as concentrações de PMl0 geralmente ficam ao redor de 10 a $20 \mu \mathrm{g} / \mathrm{m}^{3}$, enquanto em épocas de queimada podem ocorrer concentrações de pico de 500 a $1000 \mu \mathrm{g} / \mathrm{m}^{3}$ em períodos de uma a seis horas, em muitos dias. Durante o período de $1^{\circ}$ de fevereiro a 30 de abril de 1998, a média observada atingiu $109,9 \mu \mathrm{g} / \mathrm{m}^{3}$, portanto, bem acima do limite diário recomendado pela Organização Mundial de Saúde, que é de $70 \mu \mathrm{g} / \mathrm{m}^{3}$ (Radojevic \& Hassan, 1999). Foi encontrada uma variação diurna muito diferente daquela que normalmente ocorre em cidades. As concentrações aumentavam à noite, chegando a um pico no início da manhã e declinando ao meio dia. Isso poderia ser explicado por condições meteorológicas como inversões térmicas a baixas altitudes e brisa marítima. Outro ponto a destacar é que a poluição se estendia até altitudes elevadas. O 
cheiro de fumaça podia ser sentido entre 3.000 e $4.000 \mathrm{~m}$. de altitude e a uma distância de até $60 \mathrm{~km}$ do local. Os autores recomendam que, no futuro, estudos sejam feitos para detectar partículas menores que 2,5um de diâmetro pois os picos registram sobretudo partículas menores que $1 \mu \mathrm{m}$ de diâmetro. Entre os efeitos importantes dessas concentrações estão a redução da visibilidade, que pode ocasionar acidentes, os sintomas de doenças e a sujeira (Radojevic \& Hassan, 1999).

A distribuição espacial das partículas também é variável, conforme verificado na pesquisa de Muraleedharan et al. (2000) durante o mesmo episódio de 1998 em Brunei Darussalan, cujos resultados estão monstrados no quadro apresentado a seguir.

Concentrações de partículas inaláveis em suspensão (PMl0), em período de 24 horas, em três locais de amostragem em Brunei (Concentrações em $\mu \mathrm{g} / \mathrm{m}^{3}$ )

\begin{tabular}{lccc}
\hline Data & No Laboratório & No Hospital & Na Escola \\
\hline $15 / 4 / 98$ & 66 & 96 & 126 \\
$16 / 4 / 98$ & 47 & 45 & 101 \\
$17 / 4 / 98$ & 41 & 38 & 49 \\
$18 / 4 / 98$ & 77 & 130 & 228 \\
$19 / 4 / 98$ & 149 & 176 & 372 \\
\hline
\end{tabular}

Limites nos EUA (United States National Ambiente Air Quality Standard): Primário $150 \mu \mathrm{g} / \mathrm{m}^{3}$; Secundário $50 \mu \mathrm{g} / \mathrm{m}^{3}$; Recomendação OMS: $70 \mu \mathrm{g} / \mathrm{m}^{3}$ Fonte: Muraleedharan et al., 2000: 2729.

Além disso, a poluição gerada por queimadas ultrapassa fronteiras políticas, como pôde ser verificado durante o incêndio florestal ocorrido na Indonésia em 1997. Queimadas na região costeira de Sumatra tiveram impactos significativos em Singapura e em Kuala Lampur, que chegaram a apresentar concentrações diárias de PM10 de $226 \mu \mathrm{g} / \mathrm{m}^{3}$ e $416 \mu \mathrm{g} / \mathrm{m}^{3}$, respectivamente (Koe et al., 2001).

Como se depreende desses dados, as concentrações ultrapassam limites estabelecidos como proteção à saúde da população e, portanto, sujeitam tanto indivíduos saudáveis quanto aqueles de maior risco (crianças e enfermos) a efeitos prejudiciais a sua saúde e ao seu bem-estar.

A composição química desses aerossóis foi determinada em termos de porcentagem em massa, dando os seguintes resultados: $\mathrm{C}=70 \% ; \mathrm{H}=4 \% ; \mathrm{N}=2,8 \%$; 
$\mathrm{S}=4,7 \% ; \mathrm{Cl}=1, \% ; \mathrm{K}=19,9 \% ; \mathrm{Na}=3,3 \% ; \mathrm{Ca}=5,4 \% ; \mathrm{Mg}=0,05 \% ; \mathrm{Fe}=0,24 \% ; \mathrm{Cu}=0,38 \%$; $\mathrm{Zn}=19,4 \%$ (Muraleedharan et al., 2000).

A coleta de partículas de aerossóis por aviões durante o projeto Smoke, Clouds and Radiation-Brazil (SCAR-B), realizada na região amazônica em agosto e setembro de 1995, permitiu a detecção de cinco componentes principais de aerossóis: uma parcela principal (54\%) de componentes derivados de queima de biomassa; uma parcela de aerossóis provenientes de poeira do solo (15\%); componentes biogênicos naturais $(18,7 \%)$; um segundo tipo de poeira do solo enriquecida em Si, Ti e Fe (5,7\%); um componente de aerossol de $\mathrm{NaCl}$ (5,9\% da massa de aerossóis com $\mathrm{Na}, \mathrm{Cl}, \mathrm{Br}$ e iodo). Com relação ao tamanho das partículas, as mais finas representavam $78 \%$ da massa total de aerossóis e as maiores 22\% (Artaxo et al., 1998).

Portanto, como afirmado anteriormente, as partículas mais finas, presentes em maior proporção no ar poluído por queimadas, são as que mais afetam o sistema respiratório. Além disso, diferentes componentes têm efeitos específicos para a saúde. Segundo Lighty et al. (2000), a área superficial das partículas, o número de partículas ultrafinas, os metais de transição biologicamente disponíveis, os hidrocarbonetos policíclicos aromáticos (PAHs), entre outros compostos orgânicos, são suspeitos de ter maior importância do que o volume de partículas em suspensão para determinar os efeitos à saúde da poluição do ar causada por combustão e, por isso, serão discutidos em item separado.

\section{Efeitos na saude do dióxido de enxofre}

Estudos feitos com animais mostraram que a inalação de dióxido de enxofre $\left(\mathrm{SO}_{2}\right)$ pode interferir na eliminação de bactérias e partículas inertes dos pulmões. $\mathrm{SO}_{2}$ também aumenta a produção de catarro e causa maior resistência das vias aéreas.

$\mathrm{O} \mathrm{SO}_{2}$ é solúvel em meio líquido, portanto, parte dele é absorvida no nariz e na faringe, ou na boca quando se respira por ela. $\mathrm{O} \mathrm{SO}_{2}$ absorvido, então, vai para o sistema sangüíneo, distribuído por todo o corpo, sendo metabolizado e removido pelo sistema urinário. Quando a capacidade de absorção das vias aéreas superiores é ultrapassada por altas concentrações, pode ocorrer edema pulmonar e até morte (WHO, 1979).

No entanto, pesquisas realizadas durante episódios de queimadas, apesar de detectar emissões de $\mathrm{SO}_{2}$ na atmosfera, têm registrado concentrações bem abaixo daquelas recomendadas para dióxido de enxofre (4).

\section{Efeitos na saúde dos óxidos de nitrogênio}

Os óxidos de nitrogênio (NOx) tanto podem ter efeitos diretos quanto ser precursores da poluição fotoquímica (ozônio). Além disso, NOx são importantes contribuintes para a formação de chuvas ácidas, assim como o $\mathrm{SO}_{2}$. 
O óxido de nitrogênio é menos reagente que o ozônio, apesar de estudos indicarem que asmáticos e pessoas que sofrem de doenças pulmonares obstrutivas crônicas são muito sensíveis aos impactos dos NOx sobre a função pulmonar.

No entanto, medições feitas em Brunei durante queimada florestal nas imediações registraram concentrações de óxidos de nitrogênio $\left(\mathrm{NO}_{2}\right)$ de $1,5 \mu \mathrm{g} /$ $\mathrm{m}^{3}$ a $27 \mu \mathrm{g} / \mathrm{m}^{3}$, bem abaixo das recomendações feitas pela OMS (5) e dos padrões brasileiros (6) de qualidade do ar.

\section{Efeitos na saúde do ozônio}

O ozônio, próximo à superfície da terra, resulta de reações fotoquímicas de poluentes com a radiação solar e age de forma agressiva. Os oxidantes fotoquímicos produzem forte irritação nos olhos. Outras reações em altos níveis de ozônio são efeitos na função respiratória de crianças e de adultos, aumento na freqüência de ataques de asma, redução do desempenho de atletas, stress adicional em pacientes com doenças pulmonares obstrutivas crônicas, inflamação dos pulmões. Não se tem certeza sobre exposições constantes ao ozônio causarem lesões irreversíveis aos pulmões. Estão sendo desenvolvidos estudos para se avaliar os efeitos de exposições repetidas e intermitentes ao ozônio nos índices de lesão pulmonar, inflamação e fibrose (Commitee of the Environmental..., 1996).

Algumas medições realizadas durante episódios de queimadas no Sudeste Asiático, referentes à caracterização química da névoa espalhada sobre uma vasta área, indicaram concentrações de ozônio de 0,1 a $11 \mu \mathrm{g} / \mathrm{m}^{3}(0,022 \mathrm{ppm})$ em três pontos de amostragem. Tais concentrações estão abaixo das recomendações da Organização Mundial de Saúde (Muraleedharan et al., 2000) e do padrão brasileiro (7). O padrão adotado pela EPA para ozona é de $235 \mu \mathrm{g} / \mathrm{m}^{3}$ ou $0,12 \mathrm{ppm}$ em média de uma hora, a não ser excedido mais do que três vezes num período de três anos.

Outra pesquisa, realizada por Radojevic \& Hassan (1999), registrou concentrações horárias de ozônio num período de névoa causada por queimada que variaram de 5,1 a $99,9 \mu \mathrm{g} / \mathrm{m}^{3}$, com média de $63,3 \mu \mathrm{g} / \mathrm{m}^{3}$ no perío-do de $1^{\circ}$ de fevereiro a 30 de abril de 1998. Esses dados levaram os autores a afirmar que, apesar do ozônio ser produzido em incêndios florestais em diferentes quantidades, suas concentrações durante esses episódios aparentemente não apresentam riscos à saúde pública (Radojevic \& Hassan, 1999).

Pesquisas realizadas em grandes e pequenas cidades e em subúrbios de várias regiões da América do Norte indicaram concentrações de ozônio superiores a $0,12 \mathrm{ppm}$. Exposição controlada de indivíduos fazendo exercícios por algumas horas em concentrações de $0,08 p p m$ causou diminuição reversível da função pulmonar, tosse, desconforto no peito, inflamação nos pulmões. Diminuição espirométrica foi observada em crianças naturalmente expostas e em adultos em atividades externas (Committee on the Environmental..., 1996). Exercícios 
físicos aumentam a dose pulmonar por aumentarem a ventilação e alterarem o padrão de inalação e absorção nas vias aéreas. Função respiratória diminuída de atletas e crianças em atividade física foi registrada em inúmeros estudos. Com relação a efeitos crônicos, dados do National Health and Nutrition Examination Survey (NHANES II) indicaram que populações estudadas sofreram diminuição do fluxo expiratório em concentrações médias anuais de ozônio maiores que 0,04ppm, um nível considerado representativo de ar limpo (Committee of the Environmental..., 1996).

\section{Efeitos na saúde do monóxido de carbono}

O monóxido de carbono ( $\mathrm{CO}$ ) é um gás tóxico, sem cor e sem odor, que resulta da combustão incompleta do carbono em combustíveis, em incêndios, ou em queima de lenha em fogões ou lareiras. Como já mencionado, o envenenamento por $\mathrm{CO}$ é uma das causas mais freqüentes das mortes ocorridas durante incêndios florestais e os afetados principais são aqueles combatentes do fogo. Além disso, pesquisas realizadas em moradias que usam fogão a lenha para preparar as refeições registraram níveis elevados de monóxido de carbono, tanto interna quanto externamente em aglomerados de maior densidade populacional (Naeher et al., 2000). Segundo Bruce et al., (2000) há evidências que poluição interna proveniente de queima de biomassa como combustível aumenta o risco de doenças pulmonares obstrutivas crônicas e infecções respiratórias agudas em crianças.

O CO combina-se preferencialmente com a hemoglobina para produzir carboxihemoglobina $(\mathrm{COHb})$, deslocando e reduzindo o oxigênio $\left(\mathrm{O}_{2}\right)$ sistêmico arterial. Conseqüentemente, concentrações relativamente pequenas no ambiente podem causar concentrações tóxicas no sangue humano, resultando em uma molécula de hemoglobina mal equipada para liberar oxigênio aos tecidos. A menor liberação de oxigênio é detectada pelo sistema nervoso central, que estimula os esforços ventilatórios e acelera a respiração, por sua vez aumentando a inalação de monóxido de carbono e elevando os níveis de carboxihemoglobina (Varon et al., 1999).

Uma redução no nível de oxigênio nos tecidos causada por $\mathrm{COHb}$ pode ter relevantes efeitos adversos à saúde. Pequenos aumentos de carboxihemoglobina em pacientes com doenças isquêmicas do coração causam diminuição de tolerância a exercícios. Além disso, uma associação entre aumento de doenças cárdiovasculares e níveis elevados de CO no ambiente foi detectada (Committee of the Environmental..., 1996).

Efeitos tóxicos graves podem ocorrer durante incêndios, quando freqüentemente são registrados casos severos de intoxicação por $\mathrm{CO}$, incluindo lesões neurológicas que podem deixar seqüelas e causar mortes.

Em níveis mais baixos, acima de $10 \%$ de $\mathrm{COHb}$ no sangue, a poluição por monóxido de carbono pode causar dores de cabeça, náuseas e tonturas, alterar a 
percepção visual e a habilidade para realizar tarefas. Além disso, concentrações mais altas de monóxido de carbono podem afetar o desenvolvimento do feto, uma vez que a hemoglobina do feto se combina mais rapidamente com o monóxido de carbono, razão pela qual, às vezes, ocorre sua morte, enquanto a exposição não é fatal à mãe (Varon et al., 1999).

Queimadas controladas no norte da Califórnia e no Parque de Yellowstone indicaram o risco potencial do monóxido de carbono à saúde dos bombeiros, em que pesem as exposições mais altas não terem atingido os limites máximos recomendados para $\mathrm{CO}$ de $200 \mathrm{ppm}$. No entanto, os pesquisadores responsáveis informaram que as queimadas estudadas foram fracas e os bombeiros envolvidos relataram que os níveis de fumaça foram baixos e de curta duração, quando comparados com a média (Reinhart et al., 1995).

Pesquisa realizada em 1992 (Materna et al., 1992) detectou exposições elevadas de equipes de combate a incêndios na Califórnia. Reinhardt et al. (1995) concluíram que exposição prolongada à fumaça de queimadas poderia levar a doses inaladas de CO acima daquelas máximas recomendadas (8).

Durante o episódio de névoa causada em Brunei por poluição do ar proveniente de queimadas em locais próximos, no período de estiagem de $1^{\circ}$ de fevereiro a 30 de abril de 1998, mencinado, as recomendações da Organização Mundial da Saúde para limite de oito horas de monóxido de carbono $\left(10 \mu \mathrm{g} / \mathrm{m}^{3}\right.$ ou 9ppm) foram excedidas em sete ocasiões (Radojevic \& Hassan, 1999).

Considerando-se que episódios semelhantes ocorrem no Brasil, pode-se inferir que nas áreas rurais onde ocorrem queimadas e nos centros urbanos próximos a ultrapassagem dos padrões de monóxido de carbono no ar seja um fator recorrente no inverno e afete de forma crônica a população em geral e não só os combatentes de incêndios, que sofreriam de forma aguda os efeitos mais graves.

\section{Poluição do ar e riscos de neoplasias}

Um aspecto muito importante relacionado às emissões de queimadas é seu efeito a longo prazo, com aumento do risco de neoplasias pela presença de substâncias cancerígenas ou suspeitas de ação cancerígena, como as dioxinas, furanos e hidrocarbonetos policíclicos aromáticos (HPAs). Esses compostos podem estar presentes tanto no material particulado quanto na fase gasosa. $\mathrm{O}$ material particulado resultante da combustão incompleta - como a que ocorre nas queimadas - é reconhecidamente cancerígeno em animais, com possível ação cancerígena também no Homem.

As dibenzo-para-dioxinas policloradas (PCDDs) e os dibenzofuranos policlorados (PCDFs), comumente chamados de dioxinas e furanos, são duas classes de compostos aromáticos tricíclicos, de função éter, com estrutura quase planar, e que possuem propriedades físicas e químicas semelhantes. Os átomos de cloro se ligam aos anéis benzênicos, possibilitando a formação de um grande 
número de congêneres: 75 para as dioxinas e 135 para os furanos, totalizando 210 compostos. A combustão tem sido considerada a principal fonte de emissão de dioxinas e furanos para a atmosfera. Das 210 dioxinas e furanos existentes, 17 compostos com substituições na posições 2,3,7 e 8 destacam-se sob o ponto de vista toxicológico. A toxicidade aguda mais elevada é para a 2,3,7,8-tetraclorodibenzo-p-dioxina (2,3,7,8-TCDD), ultrapassada somente por algumas toxinas de origem natural (Grossi, 1993, apud Assunção \& Pesguero, 1999).

Uma reavaliação dos efeitos das dioxinas e furanos feita pela USEPA em 1994 (USEPA, 1994) concluiu que a TCDDs exercem seu efeito carcinogênico, primariamente mediante sua efetividade como agente promotor de estimulação da replicação de células numa maneira reversível. Esse mecanismo é mediado presumivelmente pelo receptor Ah (receptor de hidrocarboneto aromático) e por mecanismos transducionais associados. Portanto, as TCDDs não são carcinógenos completos e não deveriam ser designados como tal. A 2,3,7,8-TCDD, sob certas condições de exposição, é capaz de aumentar a incidência de câncer em humanos. As TCDDs estão classificados pela USEPA no grupo BI (provável carcinogênico humano com base em informação limitada de estudos em humanos assim como em animais) (USEPA/SAB 1995). Em 1997 a Organização Mundial da Saúde alterou a classificação da 2,3,7,8-TCDD de provável cancerígeno em humanos (grupo 2A) para cancerígeno ao ser humano (grupo 1) (WHO/ IARC, 2001).

Segundo Pitts (1987 apud. Vasconcellos, 1996) os HPAs são emitidos principalmente na fase gasosa, embora uma porção significante - os HPAs mais pesados - esteja associada às partículas finas carbonadas. Os HPAs podem ser convertidos nos seus derivados nitratos quando expostos a agentes, entre eles, particularmente ativos, $\mathrm{NO}, \mathrm{HNO}_{3}, \mathrm{~N}_{2} \mathrm{O}_{5}$ e radicais $\mathrm{NO}_{3}$. Os dois primeiros, que convertem os HPAs adsorvidos em partículas, estão presentes nas queimadas ou são resultantes de reações dessas emissões na atmosfera.

Algumas substâncias pertencentes à classe química dos HPAs apresentam efeitos indutores de câncer em várias espécies de animais e são suspeitas de causar câncer também em seres humanos. A Organização Mundial da Saúde, por meio da International Agency for Research on Câncer (IARC), reconheceu como prováveis agentes cancerígenos em humanos - grupo 2A - Benzo[a]antraceno, Benzo $[a]$ pireno e Dibenzo $[a, h]$ antraceno, e como possíveis agentes cancerígenos - grupo 2B - Benzo[b]fluoranteno, Benzo[ $j]$ fluoranteno, Benzo[k]fluoranteno, Dibenzo $[a, e]$ pireno, Dibenzo[a,b]pireno, Dibenzo[a,i]pireno e Dibenzo[a,l]pireno (WHO/IARC, 2001).

\section{Conclusões}

Já se tem base científica para afirmar que a poluição do ar tem efeitos negativos para a saúde humana. Os impactos decorrentes dos gases emitidos pela 
combustão de biomassa ainda não foram bem avaliados, mas afetam um número significativo de pessoas, sobretudo nos países em desenvolvimento, onde a queimada constitui uma prática agrícola bastante difundida. Além disso, incêndios em florestas ou em cerrado são constantes durante os meses de inverno, quando a reduzida precipitação leva à perda de umidade da massa vegetal, propiciando a ocorrência de queimadas involuntárias que fogem ao controle.

Esse conhecimento é importante para a definição de políticas de controle e de estabelecimento de padrões de qualidade do ar específicos para o caso das queimadas. $\mathrm{O}$ monitoramento e o estabelecimento de padrões de qualidade do ar, muito usados para avaliar e controlar a qualidade do ar urbano, mostram-se inadequados para avaliar a poluição causada por queimadas e não levam em consideração a exposição a concentrações extremamente elevadas a curto prazo.

Inúmeras questões permanecem, enquanto expressivos contingentes populacionais continuam expostos a níveis de poluição que apresentam riscos adversos à sua saúde. Além disso, há dúvidas quanto aos padrões de qualidade do ar estabelecidos nos diferentes países para poluentes urbanos serem realmente eficazes na proteção da saúde de suas populações como um todo, ou se eles foram estabelecidos considerando-se apenas as pessoas saudáveis.

Quais os impactos da poluição do ar à saúde daqueles já prejudicados por alguma doença, pela idade ou por condições sócio-econômicas? Esta parece ser uma questão a ser respondida pelas pesquisas, para que seja garantido o direito universal ao ar limpo.

Como as situações são muito dinâmicas, os estudos precisam avaliar os riscos de novos agentes e de novas situações. A avaliação das rápidas e constantes mudanças na atmosfera constitui um desafio para futuras pesquisas. Outro aspecto importante é a maior inclusão do mundo não-desenvolvido e em desenvolvimento nesses estudos.

Finalmente, estudos sobre outros efeitos da poluição do ar para a saúde, não só a saúde respiratória, são raros e preliminares. Muitos de seus resultados são evidências não-conclusivas. No futuro, há urgência na realização de estudos mais amplos, envolvendo ainda mais profissionais, de diferentes áreas.

Notas

1 Os padrões primários brasileiros para PMl0 são $150 \mu \mathrm{g} / \mathrm{m}^{3}$ diário, $50 \mu \mathrm{g} / \mathrm{m}^{3}$, anual e $250 \mu \mathrm{g} / \mathrm{m}^{3}$ nível de atenção.

$2 \mathrm{O}$ índice de qualidade do ar adotado na região é calculado com base em cinco poluentes: $\mathrm{NO}_{2}, \mathrm{SO}_{2}, \mathrm{O}_{3}, \mathrm{CO}$ e material particulado em suspensão (PMl0); vai de 0 a 500. Quando de 0 a 100, o ar é considerado bom ou regular; acima de 101 é considerado não-saudável; acima de 200, muito insalubre (Abidin \& Shin, 1996, apud FANG et al, 1999). 
3 Comunicação pessoal de médico responsável pelo Posto de Saúde da Usina Sobar, em Espírito Santo do Turvo (SP).

4 Padrões nacionais de qualidade para $\mathrm{SO}_{2}$ : primário diário $365 \mu \mathrm{g} / \mathrm{m}^{3}$, anual $80 \mu \mathrm{\mu g} /$ $\mathrm{m}^{3}$; secundário diário $100 \mu \mathrm{g} / \mathrm{m}^{3}$, anual $40 \mu \mathrm{g} / \mathrm{m}^{3}$.

$5200 \mu \mathrm{g} / \mathrm{m}^{3}$ por uma hora

6 Padrões nacionais de qualidade do ar para $\mathrm{NO}_{2}$ : primário $320 \mu \mathrm{g} / \mathrm{m}^{3}$ por uma hora e $100 \mu \mathrm{g} / \mathrm{m}^{3}$ média anual; secundário $190 \mu \mathrm{g} / \mathrm{m}^{3}$ por uma hora e $100 \mu \mathrm{g} / \mathrm{m}^{3}$ média anual

$7 \mathrm{O}$ padrão nacional de qualidade do ar para ozônio é de $160 \mu \mathrm{g} / \mathrm{m}^{3}$ por uma hora, não devendo ser excedido mais que uma vez por ano.

8 Padrões nacionais de qualidade do ar para monóxido de carbono: primário e secundário $40.000 \mathrm{\mu g} / \mathrm{m}^{3}$ ou $35 \mathrm{ppm}$ para uma hora; $10.000 \mathrm{mg} / \mathrm{m}^{3}$ ou $9 \mathrm{ppm}$ para oito horas, ambos não devendo ser excedidos mais que uma vez ao ano.

Referências Bibliográficas

ARAÚJO, T. M. et al. A tropical rainforest experiment by biomass burning in the state of Pará, Brazil. Atmospheric Environment 33, 1991-1998, 1999.

ARBEX, M. A.; BÖHM, G. M.; SALDIVA, P.H.N.; CONCEIÇÃO, G.; POPEIII, A.G. \& BRAGA, A. L. F. Assessment of the effects of sugar cane plantation burning on daily counts of inhalation therapy. Journal of the Air \& Waste Management Association 50, p. 1745-1749, Oct 2000.

ARTAXO, P.; FERNANDES, E. T.; MARTINS, J. V.; YAMASOE, M.A.; HOBBS, P.V.; MAENHAUT, W.; LONGO, K. M. \& CASTANHO, A. Large-scale aerosol source apportionment in Amazonia. Journal of Geophysical Research- D: Atmospheres, v. 103, n.24, p. 31837-31847, Dec. 1998.

ASSUNÇÃO, J.V. \& PESQUERO, C.R. Dioxinas e furanos: origens e riscos. Revista de Saúde Pública, v. 33, n. 5, São Paulo, 1999.

AUDY, J.R. Measurement and diagnosis of health. In Shepard, P. \& McKinley, D. (eds.) Environ/mental. essays on the planet as a home. New York, Houghton Mifflin, 1971.

BRUCE, N.; PEREZ-PADILLA, R. \& ALBALAK, R. Indoor air pollution in developing countries: a major environmental and public health challenge. Bulletin of the World Health Organization, v 78, n. 9, p. 1078-1092, 2000.

CETESB (Companhia de Tecnologia de Saneamento Ambiental). Relatório de Qualidade do Ar no Estado de São Paulo-1998. São Paulo, CETESB, 1999.

CHAN, N.Y.; EBI, K.L.; SMITH, F.; WILSON, T.F. \& SMITH, A.E. An integrated assessment framework for climate change and infectious diseases. Environmental Health Perspectives, v. 107, n. 5, May 1999. 
COCHRANE, M.A. O significado das queimadas na Amazônia. Ciência Hoje, v. 27, n. 157, SBPC, S. Paulo, jan./fev. 2000.

COMMITTEE OF THE ENVIRONMENTAL and Occupational Health Assembly of the American Thoracic Society. Health effects of outdoor air pollution: state of the art. American Journal of Respiratory and Critical Care Medicine, v. 153, p. 3-50; 477-498, 1996.

CONARD, S.G. \& IVANOVA, G. A. Wildfire in Russial boreal forests: potential impacts of fire regime characteristics on emissions and global carbon balance estimates. Environmental Pollution, v. 98, n. 3, p. 305-313, Elsevier, Great Britain, 1997.

DUBOS, R. Man adapting. New Haven, Yale University Press, 1961.

ECK, T.F.; HOLBEN, B.N.; SLUTSKER, I. \& SETZER, A. Measurements of irradiance attenuation and estimation of aerosol single scattering albedo for biomass burning aerosols in Amazonia. Journal of Geophysical Research- D: Atmospheres, v. 103, n. 24, p. 31865-31878, Dec., 1998.

FANG, M.; ZHENG, M.; WANG, F.; TO, K.L.; JAAFAR, A.B. \& TONG, S.L. The solvent-extractable organic compounds in the Indonesia biomass burning aerosolscharacterization studies. Atmospheric Environment, 33, p. 783-795, Pergamon, 1999.

JENKINS, B.M. et al. Atmospheric emissions from agricultural burning in California: determination of burn fractions, distribution factors, and crop-specific contributions. Agriculture, Ecosystems and Environment, 38, p. 313-330, 1992.

KAUFMAN, Y.J.; HOBBS, P.V.; KIRCHHOFF, V.W.J.H.; ARTAXO, P.; RMER, L.A.; HOLBEN, B.N.; KING, M.D.; WARD, D.E.; PRINS, E.M.; LONGO, K.M.; MATTOS, L.F.; NOBRE, C.A.; SPINHINE, J.D.; JI, Q.; THOMPSON, A.M.; GLEASON, J.F.; CHRISTOPHER, S.A. \& TSAY, S.C. Smoke, clouds and radiation (SCAR-B) experiment. Journal of Geophysical Research D: Atmospheres, n. 103, n. 24, p. 31, 78331, 808, Dec 27, 1998.

KIRCHOFF, V. Revista Espacial. Ano XVIII, n. 74. INPE, ago. 1989.

KOE, L.C.C.; ARELLANO JR., A.F. \& McGREGOR, J.L.. Investigating the haze transport from 1977 biomass burning in Southeast Asia: its impact upon Singapore. Atmospheric Environment, 35, p. 2723-2734, Elsevier, 2001.

LIGHTY, J.S.; VERANTH, J.M. \& SAROFIM, A.F. Combustion aerosols: factors governing their size and composition and implications to human health. Journal of the Air e Waste Management Association, v. 50, n. 9, p. 1565-1618, Pittsburg, Sept. 2000.

MATERNA, B.L.; JONES, J.R.; SUTTON, P.M.; ROTHMAN, N. \& HARRISON, R.J. Occupational exposures in California wildlife firefighting. American Industrial Hygeine Association Journal, v. 53, n. 1, p. 69-76, 1992.

MIRANDA, E.E.; DORADO, A.J. \& ASSUNÇÃO, J.V. Doenças respiratórias crônicas em quatro municipios paulistas, 2. ed. Ecoforça, USP/Unicamp, 1995, 139 p.

MURALEEDHARAN, T.R.; RADOJEVIC, M.; WAUGH, A. \& CARUANA, A. Chemical characterisation of the haze in Brunei Darussalam during the 1998 episode. Atmospheric Environment, 34, p. 2725-2731, Pergamon Elsevier, 2000. 
NAEHER, L.P.; SMITH, K.R.; LEADERER, B.P.; MAGE, D. \& GRAJEDA, R. Indoor and outdoor PM2.5 and CO in high - and low - density Guatemalan villages. Journal of Exposure Analysis and Environmental Epidemiology, v. 10, n. 6, p. 544-551, part 1, Nov./Dec. 2000.

NASCIMENTO, M.T.; FELFITI, J.M.; OLIVEIRA F'., A.T.; LEITE FONTES, M.A.; FRANÇA, J.T.; HAY, J. \& GRIBEL, R. Efeitos do fogo nas florestas. Ciência Hoje, v. 27, n. 157. SBPC, jan./fev. 2000.

NOBRE, C.A.; MATTOS, L.F.; DERECZYNSKI, C.P.; TARASOVA, T.A. \& TROSNIKOV, I.V. Overview of atmospheric conditions during the smoke, clouds and radiation- Brazil (SCAR-B) field experiment. Journal of Geophysical Research D: Atmospheres, v. 103, n. 24, p. 31, 809, 31, 820, Dec. 271998.

RADOJEVIC, M. Burning issues. Chemestry in Britain, v. 34, n. 12, p. 38-42, 1998.

RADOJEVIC, M. \& HASSAN, H. Air quality in Brunei Darussalam during the 1998 haze episode. Atmospheric Environment, v. 33, n. 22, p. 3651-3658, 1999.

REINHARDT, T.; BLACK, J. \& OTTMAR, R.D. Smoke exposure at Northern California vegetation fires. Seattle, WA., USDA Forest Service, Pacific Northwest research station, 1995.

RIBEIRO, H. Fossil fuel energy impacts on health. Encyclopedia of Life Support Systems. Unesco, 2001a.

Análise espacial e saúde pública. In Dowbor, L. (ed.) Economia Social no Brasil. São Paulo, SENAC, 2001 b.

STOLLE, F. \& TOMICH, T.P. The 1997-1998 fire event. Nature \& Resources, v. 35, n. 3, p. 22-30. Paris, Unesco, Jul./Sept. 1999.

USEPA. United Stats Environmental Protection Agency. Compilation of air pollutant emission factors (AP42). Wildfires and prescribed burning. Washington D.C., USEPA, 1996.

USEPA/SAB. United States Environmental Protection Agency/Science Advisory Board. Dioxin Reassessment Review. Washington D.C., USEPA, <URL:http:/www.epa.gov/ doc/SAB-Reports Dioxin.txt.html> (1997 Aug. 31).

USEPA. United States Environmental Protection Agency. Health Assessment document for 2,3,7,8-tetrachlorodibenzeno-p-dioxin (TCDD) and related compounds. Washington D.C., USEPA (EPA/600/BP-92/001), 1994.

VARON, J.; MARIK, P.E.; FROMM, R.E. \& GUELER, A. Carbon monoxide poisoning: a review for clinitians. The Journal of Emergency Medicine, v. 17, n. 1, p. 87-93, Elsevier, USA, 1999.

VASCONCELLOS, P.C. Um estudo sobre a caracterização de hidrocarbonetos policiclicos aromáticos e seus derivados e hidrocarbonetos alifáticos saturados em material particulado atmosférico proveniente de sitios urbanos, suburbanos e florestais. São Paulo, 1996. Tese (doutorado), Instituto de Química da Universidade de São Paulo. 
WEIHE, W.H. Life Expectancy In Tropical Climates and Urbanization. Urban Climatology and its Applications with Special Regard to Tropical Areas Conference. Mexico, D.F., Nov. 1984. Genéve, WMO n. 652, 1986.

WHO. World Health Organisation. Sulfur oxides and suspended particulate matter. Environmental Health Criteria, 8, Genève, 1979. Guidelines for Air Quality. WHO, Genève, 2000.

WHO/IARC. World Health Organisation/International Agency for Research on Cancer. Overall e valuations of carcinogenicity to humans. WHO, Genève, Apr. 2001. (http:/ Lwww.iarc.fr Aug. 25 2001.)

YAMASDE, E., M.A.; ARTAXO, P.; MIGUEL, A.H. \& ALLEN, A.G. Chemical composition of aerosol particles from direct emissions of vegetation fires in the Amazon Basin: water-soluble species and trace elements. Atmospheric Environment, 34, p. 16411653, Elsevier, Great Britain, 2000.

Helena Ribeiro (lena@usp.br), professora associada, e João Vicente de Assunção, professor doutor, ambos do Departamento de Saúde Ambiental da Faculdade de Saúde Pública da USP. 